\title{
Angka Kejadian Delirium dan Faktor Risiko di Intensive Care Unit Rumah Sakit Dr. Hasan Sadikin Bandung
}

\author{
Rakhman Adiwinata, ${ }^{1}$ Ezra Oktaliansah, ${ }^{2}$ Tinni T. Maskoen ${ }^{2}$ \\ ${ }^{1}$ Rumah Sakit Mata Cicendo Bandung, ${ }^{2}$ Departemen Anestesiologi dan Terapi Intensif \\ Fakultas Kedokteran Universitas Padjadjaran/Rumah Sakit Dr. Hasan Sadikin Bandung
}

\begin{abstract}
Abstrak
Delirium ditandai dengan perubahan status mental, tingkat kesadaran, serta perhatian yang akut dan fluktuatif. Keadaan ini merupakan kelainan yang serius berhubungan dengan pemanjangan lama perawatan di Intensive Care Unit (ICU), biaya yang lebih tinggi, memperlambat pemulihan fungsional, serta peningkatan morbiditas dan mortalitas. Tujuan penelitian adalah mengetahui angka kejadian delirium dan faktor risiko terjadinya delirium di ICU Rumah Sakit Dr. Hasan Sadikin (RSHS) Bandung. Pengambilan sampel dilakukan selama tiga bulan (Januari-Maret 2015) di ICU RSHS Bandung. Metode penelitian ini deskriptif observasional secara kohort prospektif, menggunakan alat ukur Confusion Assessment Method-Intensive Care Unit (CAMICU), sebelumnya dilakukan penilaian dengan Richmond agitation-sedation scale (RASS) pada pasien yang tersedasi. Hasil penelitian ini dari 105 pasien, 22 pasien dieksklusikan, dari 83 pasien didapatkan 31 pasien positif delirium, angka kejadian 37\%. Faktor-faktor risiko pada pasien positif delirium terdiri atas geriatri 15 dari 31, pemakaian ventilator 12 dari 31, pemberian analgesik morfin 9 dari 31, sepsis atau infeksi 9 dari 31, kelainan jantung 8 dari 31, acute physiology and chronic health evaluation (APACHE) II skor tinggi 8 dari 31, kelainan ginjal 7 dari 31, laboratorium abnormal 7 dari 31, pemberian sedasi midazolam 6 dari 31 kelainan endokrin 5 dari 31, pemberian analgesik fentanil 2 dari 31, dan strok 1 dari 31. Simpulan, angka kejadian delirium di ICU RSHS Bandung cukup tinggi sebesar 37\% dengan faktor risiko terbesar adalah pasien geriatrik.
\end{abstract}

Kata kunci: Confusion Assessment Method-Intensive Care Unit, delirium, faktor risiko, Richmond agitationsedation scale

\section{Incidence and Risk Factors of Deliriumin in the Intensive Care Unit of Dr. Hasan Sadikin General Hospital Bandung}

\begin{abstract}
Delirium ditandai dengan perubahan status mental, tingkat kesadaran, serta perhatian yang akut dan fluktuatif. Keadaan ini merupakan kelainan yang serius berhubungan dengan pemanjangan lama perawatan di Intensive Care Unit (ICU), biaya yang lebih tinggi, memperlambat pemulihan fungsional, serta peningkatan morbiditas dan mortalitas. Tujuan penelitian adalah mengetahui angka kejadian delirium dan faktor risiko terjadinya delirium di ICU Rumah Sakit Dr. Hasan Sadikin (RSHS) Bandung. Pengambilan sampel dilakukan selama tiga bulan (Januari-Maret 2015) di ICU RSHS Bandung. Metode penelitian ini deskriptif observasional secara kohort prospektif, menggunakan alat ukur Confusion Assessment Method-Intensive Care Unit (CAMICU), sebelumnya dilakukan penilaian dengan Richmond agitation-sedation scale (RASS) pada pasien yang tersedasi. Hasil penelitian ini dari 105 pasien, 22 pasien dieksklusikan, dari 83 pasien didapatkan 31 pasien positif delirium, angka kejadian 37\%. Faktor-faktor risiko pada pasien positif delirium terdiri atas geriatri 15 dari 31, pemakaian ventilator 12 dari 31, pemberian analgesik morfin 9 dari 31, sepsis atau infeksi 9 dari 31, kelainan jantung 8 dari 31, acute physiology and chronic health evaluation (APACHE) II skor tinggi 8 dari 31, kelainan ginjal 7 dari 31 laboratorium abnormal 7 dari 31, pemberian sedasi midazolam 6 dari 31 kelainan endokrin 5 dari 31, pemberian analgesik fentanil 2 dari 31, dan strok 1 dari 31. Simpulan, angka kejadian delirium di ICU RSHS Bandung cukup tinggi sebesar 37\% dengan faktor risiko terbesar adalah pasien geriatrik.
\end{abstract}

Keywords: Confusion AssessmentMethode-IntensiveCareUnit, delirium, Richmondagitation-sedationscale, risk factor

Korespondensi: Rakhman Adiwinata, dr., SpAn, PMN Rumah Sakit Mata Cicendo Bandung, Jl. Cicendo No. 4 Bandung, Tlpn (022) 423-1280, Mobile 081248668051, Email rakhman_dr@yahoo.com 


\section{Pendahuluan}

Delirium merupakan suatu sindrom serebral organik dengan penyebab yang tidak spesifik. Karakteristik delirium adalah gangguan fungsi kesadaran, atensi, persepsi, berpikir, memori, psikomotor, emosi, serta pola tidur-bangun. ${ }^{1}$ Delirium pascaoperasi adalah perubahan akut pada karakteristik kognisi dengan fluktuasi kesadaran serta kurangnya perhatian dalam 30 hari. Delirium emergensi sama seperti delirium pascaoperasi, namun terjadi segera pada fase pemulihan dari anestesia. ${ }^{2}$

Delirium dapat ditandai dengan perubahan status mental, kesadaran, dan juga perhatian yang bersifat akut serta fluktuatif. Delirium memiliki insidensi yang tinggi pada pasien dengan penyakit kritis. Delirium merupakan kelainan serius yang berhubungan dengan pemanjangan lama perawatan di ruang rawat intensif/rumah sakit, biaya yang lebih tinggi, memperlambat pemulihan fungsional, dan peningkatan morbiditas serta mortalitas. ${ }^{1-4}$ Tandayangberfluktuasimenyebabkan delirium sulit diketahui. Satu penelitian menunjukkan bahwa dokter tidak mendiagnosis delirium pada $32 \%$ pasien delirium dan yang lainnya mendiagnosis delirium sebagai depresi $40 \%$. Beberapa bentuk menunjukkan gambaran hiperaktif (agitasi, takikardia, dan gemetar), hipoaktif (tenang, pasif), dan campuran. ${ }^{1-4}$

Terdapat beberapa alat ukur untuk menilai delirium pada pasien dengan penyakit kritis. Confusion Assessment Method-Intensive Care Unit (CAM-ICU) memiliki tingkat sensitivitas $81 \%$ dan spesifisitas tertinggi $96 \%{ }^{2}$ Skrining pasien dalam perawatan intensif merupakan hal yang penting sehingga dapat dilakukan penatalaksanaan yang berkesinambungan. Pengukuran delirium untuk preventif dapat pula menurunkan insidensi, keparahan, dan durasi delirium., ${ }^{9,10}$ Perangkat penilaian yang sering digunakan dalam praktik klinis di Inggris adalah CAM-ICU yang telah divalidasi secara spesifik untuk digunakan di unit perawatan intensif. Alat ini mudah dan cepat digunakan dan memiliki reliabilitas antarpengamat yang baik, dapat dilakukan tiap 24 jam, menilai secara langsung, dan dapat pula digunakan saat ventilasi mekanik. ${ }^{5-7}$

Skala sedasi dipergunakan di ICU untuk mengukur kedalaman sedasi dari obat sedasi yang diberikan. Richmond agitation-sedation scale (RASS) mempunyai beberapa kualifikasi positif karena skala ini mudah digunakan dan tidak memerlukan skala tambahan. Penilaian sedasi dapat dikerjakan dalam 30-60 detik. Skala ini juga tidak membutuhkan peralatan tambahan, mudah untuk dipelajari, dan mudah diingat karena strukturnya yang logis. Skala RASS juga berbeda dengan skala yang lain karena memisahkan antara rangsang suara, fisik, dan lamanya kontak mata. Berdasar atas fakta bahwa kondisi pasien bersifat dinamis dan skala RASS memiliki kemampuan untuk mengukur tingkat kesadaran dari waktu ke waktu bila dilakukan secara terus menerus. ${ }^{8}$

Terlepas dari fakta bahwa delirium adalah pengalaman yang sangat tidak menyenangkan untuk pasien dan keluarga, tenaga medis juga menyadari konsekuensi yang terjadi, bukan hanya lama perawatan yang memanjang, tetapi masalah pascapemulangan dari rumah sakit, defisit kognitif jangka panjang, dan mortalitas harus dipertimbangkan. Saat ini pemahaman tentang penyebab pasien mengalami delirium masih terbatas. ${ }^{1,4}$

Risiko terjadi delirium diinterpretasikan sebagai pengaruh dari faktor predisposisi dan faktor presipitasi. Pasien dengan beberapa atau tanpa faktor predisposisi akan terjadi delirium hanya bila terdapat faktor presipitasi yang kuat, sedangkan pasien dengan beberapa faktor predisposisi akan terjadi delirium setelah ada faktor presipitasi yang ringan saja. Terdapat faktor protektif yang dapat melawan faktor predisposisi atau pengaruh kuat dari faktor presipitasi. ${ }^{1,4}$

Tujuan penelitian ini adalah mengetahui angka kejadian dan faktor risiko delirium di Intensive Care Unit (ICU) Rumah Sakit Dr. Hasan Sadikin (RSHS) Bandung.

\section{Subjek dan Metode}

Penelitian ini merupakan penelitian deskriptif observasional secara kohort prospektif yang dilakukan setelah mendapat persetujuan dari 
Komite Etik Penelitian Kesehatan Fakultas Kedokteran Universitas Padjadjaran/Rumah Sakit Dr. Hasan Sadikin Bandung. Penelitian dilakukan pada bulan Januari-Maret 2015 dengan kriteria inklusi adalah semua pasien dewasa yang dirawat di ICU RSHS Bandung dan pasien yang memiliki nilai RASS $\leq-3$. Kriteria eksklusi adalah pasien yang dirawat $\leq 24$ jam di ICU dan pasien yang memiliki gangguan pedengaran dan juga gangguan penglihatan. Kriteria pengeluaran adalah sejawat dokter atau tenaga medis yang dirawat di ICU RSHS Bandung.

Penelitian dilakukan pada semua pasien dewasa yang dirawat di ICU RSHS Bandung. Pemeriksaan RASS dilakukan terhadap semua pasien terutama pada pasien yang tersedasi, bila pasien memiliki nilai RASS +4 sampai dengan -3 maka pemeriksaan dilanjutkan dengan CAM-ICU untuk menilai terjadinya delirium, namun bila pasien dalam keadaan agitasi atau tersedasi dalam (nilai RASS $\leq-4$ ) sehingga pasien tidak dapat berkomunikasi dengan baik atau tidak kooperatif maka pemeriksaan dihentikan sampai pasien dapat diajak komunikasi dengan baik. Observasi pasien dilakukan minimal sehari dua kali penilaian hingga ditemukan kejadian delirium atau tidak sampai 30 hari bila pasien masih dirawat di ICU.

Analisis statistik dilakukan dengan analisis deskriptif yang memberikan gambaran angka

Tabel 1 Karakteristik Subjek Penelitian dan Kejadian Delirium

\begin{tabular}{lcc}
\hline Karakteristik & $\begin{array}{c}\text { Jumlah } \\
\text { Pasien } \\
\text { (n=83) }\end{array}$ & $\begin{array}{c}\text { Jumlah } \\
\text { Pasien } \\
\text { Positif } \\
\text { Delirium } \\
\text { (n=31) }\end{array}$ \\
\hline Usia pasien & & \\
Mean \pm SD & $45,75 \pm 17,56$ & $57,42 \pm 17,14$ \\
Median & 43,00 & 66,00 \\
Range & 63,00 & 57,00 \\
Jenis kelamin & & 18 \\
Laki-laki & 38 & 13 \\
Perempuan & 45 & \\
\hline
\end{tabular}

kejadian delirium serta faktor risikonya pada pasien yang dirawat di ruang perawatan intensif RSHS Bandung. Data yang diperoleh diolah melalui program statistical product and service solution (SPSS) versi 21.0 for windows.

\section{Hasil}

Karakteristik umum subjek penelitian ini didapatkan pasien yang mengalami delirium sebanyak 31 orang dengan jenis kelamin lakilaki (18 orang) lebih banyak dibanding dengan pasien perempuan (13 orang; Tabel 1). Angka kejadian delirium pada pasien pascaoperasi lebih besar daripada pasien medikal (Tabel 2).

Tingkat kesadaran yang banyak terdeteksi pada pasien yang positif delirium tergolong tipe hipoaktif, yaitu kompos mentis sampai dengan somnolen (Tabel 3). Angka kejadian mortalitas pada pasien positif delirium lebih tinggi dibanding dengan pasien yang tidak terdeteksi delirium (Tabel 4). Pada penelitian ini faktor risiko geriatrik merupakan faktor risiko terbesar pada pasien positif delirium (Tabel 5).

\section{Pembahasan}

Penelitian ini dilakukan terhadap 105 pasien dewasa pascaoperasi dan pasien medikal yang dirawat di ICU Rumah Sakit Dr. Hasan Sadikin Bandung. Setelah dilakukan penilaian dengan RASS diperoleh 83 pasien dewasa yang memenuhi kriteria inklusi dan bersedia menjadi subjek penelitian, sebanyak 22 pasien dieksklusikan, kemudian dilakukan penilaian delirium dengan CAM-ICU dan diperoleh 31 pasien positif delirium.

Tabel 2 Angka Kejadian Delirium pada Pasien Pascaoperasi dan Medikal

\begin{tabular}{lcc}
\hline Tipe Pasien & $\begin{array}{c}\text { Jumlah Pasien } \\
\text { (n=83) }\end{array}$ & $\begin{array}{c}\text { Jumlah } \\
\text { Pasien } \\
\text { Positif } \\
\text { Delirium } \\
\text { (n=31) }\end{array}$ \\
\hline Pascaoperasi & 59 & 17 \\
Medikal & 24 & 14 \\
\hline
\end{tabular}


Tabel 3 Angka Tingkat Kesadaran pada Keseluruhan Pasien

\begin{tabular}{lcc}
\hline $\begin{array}{c}\text { Tingkat } \\
\text { Kesadaran }\end{array}$ & $\begin{array}{c}\text { Jumlah } \\
\text { Pasien } \\
\text { (n=83) }\end{array}$ & $\begin{array}{c}\text { Jumlah } \\
\text { Pasien Positif } \\
\text { Delirium } \\
\text { (n=31) }\end{array}$ \\
\hline Agitasi & 1 & 1 \\
Kompos mentis & 70 & 18 \\
Apatis & 3 & 3 \\
Somnolen & 9 & 9 \\
\hline
\end{tabular}

Delirium memiliki insidensi yang tinggi pada pasien sakit kritis. Hal ini merupakan kelainan serius yang berhubungan dengan pemanjangan lama perawatan di unit perawatan intensif (ICU) rumah sakit, biaya yang lebih tinggi, memperlambat pemulihan fungsional, dan peningkatan angka morbiditas dan mortalitas. Tanda-tanda yang berfluktuasi menyebabkan delirium sulit diketahui, CAMICU mempunyai tingkat sensitivitas $81 \%$ dan spesifisitas tertinggi $96 \%$ yang telah divalidasi secara spesifik untuk dapat digunakan di unit perawatan intensif. Alat ini mudah dan cepat untuk digunakan, serta memiliki reliabilitas antarpengamat yang baik, dapat dilakukan tiap 24 jam untuk menilai pasien secara
Tabel 4 Angka Kejadian Mortalitas pada Pasien Delirium Positif dan Delirium Negatif

\begin{tabular}{lcc}
\hline $\begin{array}{c}\text { Keadaan } \\
\text { Pasien }\end{array}$ & $\begin{array}{c}\text { Delirium } \\
\text { Positif } \\
\text { (n=31) }\end{array}$ & $\begin{array}{c}\text { Delirium } \\
\text { Negatif } \\
\text { (n=52) }\end{array}$ \\
\hline Hidup & 23 & 50 \\
Meninggal & 8 & 2 \\
\hline
\end{tabular}

langsung maupun saat ventilasi mekanik.

Padakarakteristikumum subjek didapatkan jumlah laki-laki yang positif delirium lebih banyak dibanding dengan perempuan, angka kejadian pada pasien pascaoperasi didapatkan lebih besar dibanding dengan pasien medikal. Hal tersebut juga didapatkan pada beberapa penelitian lain.., 9

Tingkat kesadaran pada pasien delirium pada penelitian ini paling banyak adalah kompos mentis, apatis, dan somnolen. Hal ini juga didapatkan pada beberapa penelitian lain bahwa delirium tipe hipoaktif lebih banyak terdeteksi dibanding dengan tipe hiperaktif atau tipe campuran. ${ }^{5,9}$

Angka mortalitas pada pasien delirium lebih tinggi (8 orang) dibanding dengan pasien yang tidak delirium ( 2 orang). Hal ini juga

Tabel 5 Faktor-faktor Risiko yang Didapat pada Keseluruhan Pasien

\begin{tabular}{|c|c|c|}
\hline Variabel & $\begin{array}{c}\text { Delirium Positif } \\
(n=31)\end{array}$ & $\begin{array}{c}\text { Jumlah Pasien } \\
(n=83)\end{array}$ \\
\hline Geriatrik & 15 & 17 \\
\hline Ventilator & 12 & 23 \\
\hline Analgesik morfin & 9 & 10 \\
\hline Pasien sepsis & 9 & 10 \\
\hline Kelainan jantung & 8 & 9 \\
\hline Apache II skor tinggi & 8 & 8 \\
\hline Kelainan ginjal & 7 & 9 \\
\hline $\begin{array}{l}\text { Laboratorium abnormal (uremikum, anemia, hiperglikemia, } \\
\text { dan asidosis) }\end{array}$ & 7 & 7 \\
\hline Sedasi midazolam & 6 & 6 \\
\hline Kelainan endokrin & 5 & 5 \\
\hline Analgesik fentanil & 2 & 3 \\
\hline Strok & 1 & 1 \\
\hline
\end{tabular}


didapatkan pada beberapa penelitian lain. ${ }^{9}$

Faktor risiko delirium merupakan hasil dari faktor predisposisi dan faktor presipitasi. Pasien dengan beberapa atau tanpa faktor predisposisi akan terjadi delirium hanya bila ada faktor presipitasi yang kuat, sedangkan pasien dengan beberapa faktor predisposisi akan mengalami delirium setelah ada faktor presipitasi yang ringan saja. Namun, terdapat faktor protektif yang dapat melawan faktor predisposisi atau pengaruh kuat dari faktor presipitasi.

Pasien geriatrik merupakan faktor risiko terbesar pada pasien delirium, diikuti dengan pemakaian ventilator dan pemberian analgesik morfin, sedangkan pasien strok sebagai faktor risiko terkecil pada penelitian ini. Hal serupa didapatkan pada penelitian yang lain. ${ }^{5}$

Penyebab delirium menurut salah satu teori adalah terdapatnya defisiensi neurotransmiter asetikolin serta dopaminergik. Pada geriatrik terdapat defisiensi relatif asetilkolin hasil metabolisme oksidatif otak sehingga terjadi disfungsi mental. Neurotransmiter asetilkolin berperanan sangat penting dalam awareness. Dopamin adalah neurotransmiter yang sangat penting bagi fungsi motorik, perhatian, serta kognisi. Reseptor dopamin terdiri atas dua tipe, yaitu reseptor D1 dan reseptor D5. Aktivasi tipe D1 (reseptor D1 dan D5) meningkatkan sekresi asetilkolin, sedangkan aktivasi tipe D2 (reseptor D3 dan D4) menurunkan sekresi asetilkolin. Jumlah D1 dan D2 menurun dengan meningkatnya usia yang dapat meningkatkan kemungkinan delirium pada geriatik. ${ }^{1}$

Pada pasien dengan pemakaian ventilator akan merasakan ketidaknyamanan disebabkan oleh pipa endotrakeal dan pergerakan pasien yang terbatas (imobilisasi). Untuk mengatasi hal tersebut diberikan obat sedasi agar pasien tenang. Hal tersebut akan mengganggu pola tidur-bangun pasien sehingga memperpanjang lama perawatan di ruang perawatan intensif dan meningkatkan angka kejadian delirium. ${ }^{1}$

Pasien dengan pemberian analgesik morfin meningkatkan kejadian delirium disebabkan obat ini melewati sawar darah otak sehingga akan meningkatkan pelepasan dopamin dan menghambat neuron noradrenalin penyebab delirium. ${ }^{1}$

\section{Simpulan}

Angka kejadian delirium di ICU RSHS adalah 37\%. Faktor-faktor risiko delirium di ruang rawat intensif RSHS Bandung adalah geriatrik, pemakaian ventilator, pemberian morfin, sepsis atau infeksi, kelainan jantung, skor Apache II tinggi, kelainan ginjal, laboratorium abnormal (uremikum, anemia, hiperglikemia, dan asidosis), pemberian obat sedasi, kelainan endokrin, pemberian fentanil, dan strok.

\section{Daftar Pustaka}

1. Steiner LA. Postoperative delirium. Part 1: pathophysiology and risk factor. Eur J Anaesthesiol. 2011;28(9):628-36.

2. Steiner LA. Postoperative delirium. Part 2: detection, prevention, and treatment. Eur J Anesthesiol. 2011;28(10):723-32.

3. American Psychiatric Association Diagnostic and Statistical Manual of Mental Disorders (DSM-IV). Edisi ke-4. United States: APA; 2006.

4. Connor D, Williams E. Delirium in critical care. Intensive care medicine. Royal Cornwall Hospital UK. 2011;18:232.

5. Boogaard VM, Pickkers P, van der Hoeven H, Roodbol G, Achterberg VT, Schoonhoven L. Development and validation prediction of delirium in ICU patients. BMJ. 2012;344:420.

6. Ouimet S, Kavanagh BP, Gottfried SB, Skrobik Y. Incidence, risk factors and consequencesof ICU delirium. Intens Care Med. 2007;33:66-73.

7. Luetz A, Heymann A, Radtke FM, Chenitir C, Neuhaus U, Nachtigall I, dkk. Different assessment tools for intensive care unit delirium: which score to use?. Crit Care Med. 2010;38:409-18.

8. Suhandoko, Pradian E, Maskoen TT. Reabilitas dan validasi penilaian skala sedasi richmond agitation sedation scale (RASS) dan ramsay pada pasien kritis dengan ventilasi mekanik di ruang perawatan intensif. JAP. 2014;2(3):186- 
93.

9. Thomason JW, Shintani A, Peterson JF, Pun BT, Jackson JC, Ely EW. Intensive care unit delirium is an independent predictor of longer hospital stay: a prospective analisis of 261 non-ventilated patients. Crit Care. 2005;9:375-81. 